
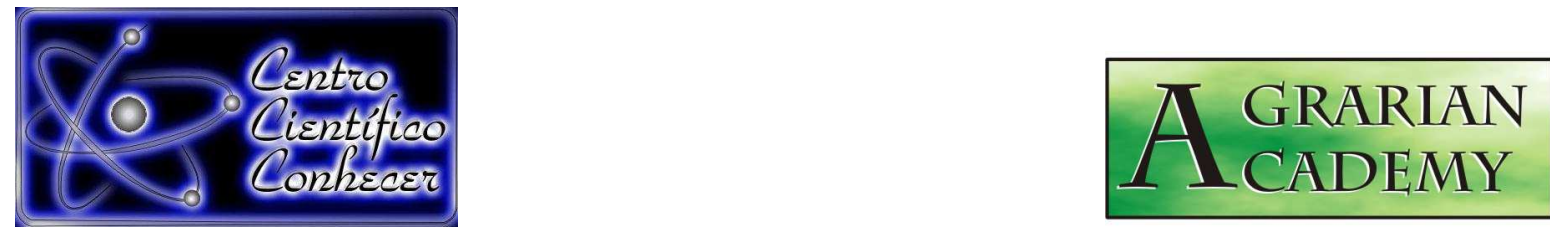

\title{
PRODUÇÃO DE GRÃOS COMERCIAIS E INADEQUADOS DE AMENDOIM EM FUNÇÃO DO SISTEMA DE CULTIVO E DO ESPAÇAMENTO ENTRE PLANTAS
}

\author{
Laura Leopoldina Sousa ${ }^{1}$; Kelly Naiana Lima Araujo²; Nerton Da Penha Filho²; Antônio \\ Alves Pinto ${ }^{2}$; Felipe Thomaz Da Camara ${ }^{3}$ \\ ${ }^{1}$ Graduanda e bolsista do Programa de Educação Tutorial (Pet) da Agronomia pela \\ Universidade Federal do Cariri, Crato-CE, Brasil, (lauraleopoldinas@gmail.com); \\ ${ }^{2}$ Graduando(a) e bolsista do Pet da Agronomia pela Universidade Federal do Cariri, Crato- \\ CE, Brasil; \\ ${ }^{3}$ Professor Adjunto e Tutor do Pet Agronomia da Universidade Federal do Cariri, Crato-CE,
} Brasil.

Recebido em: 30/11/2017 - Aprovado em: 15/12/2017 - Publicado em: 31/12/2017 DOI: 10.18677/Agrarian Academy 2017b21

\begin{abstract}
RESUMO
O amendoim (Arachis hypogaea $\mathrm{H}$.) é uma leguminosa originária do sul da América que apresenta importância para o Brasil e o mundo devido a sua qualidade nutricional. Pode ser cultivado em sistema de sequeiro ou irrigado e o espaçamento é um dos fatores que influencia diretamente o aproveitamento dos elementos ambientais disponíveis. Portanto, o objetivo desse trabalho foi avaliar a influencia do sistema de cultivo irrigado e sequeiro e o espaçamento entre as plantas na produção de grãos comerciais, grãos inadequados e a porcentagem destes grãos. O delineamento utilizado foi em blocos casualizados, em esquema de parcela subdividida, com quatro repetições. A parcela foi o sistema de cultivo do amendoim (gotejo suplementar e sequeiro), e a subparcela foi o espaçamento entre plantas (10 e $20 \mathrm{~cm}$ ). As variáveis analisadas foram o número e a massa de grãos comerciais e inadequados. Os resultados evidenciaram que não ocorreu interação significativa entre os fatores sistema de cultivo e espaçamento entre as plantas para todas variáveis analisadas. Conclui-se que não houve efeito significativo do espaçamento entre as plantas sobre a produção de grãos comerciais e inadequados, e o sistema de gotejo foi superior quanto à produção de grãos comerciais e inadequados, com menor porcentagem de grãos inadequados do que o sistema de sequeiro.
\end{abstract}

PALAVRAS-CHAVE: Densidade de plantas. Gotejo. Sequeiro.

\section{PRODUCTION OF COMMERCIAL GRAINS AND NUTS OF PEANUTS IN THE FUNCTION OF THE CULTURE SYSTEM AND PLANT SPACING}

\begin{abstract}
The peanut (Arachis hypogaea $\mathrm{H}$.) is a leguminous native of the South of America that presents importance to Brazil and the world due to its nutritional quality. It can be cultivated in a rainfed or irrigated system and spacing is one of the factors that directly influences the use of available environmental elements. Therefore, the
\end{abstract}


objective of this work was to evaluate the influence of the irrigated and dry cropping system and the spacing between the plants in the production of commercial grains, bad grains and the percentage of bad grains. The experimental design was a randomized complete block design with four replications. The plot was the peanut cultivation system (Supplementary drip and dry land), and the subplot was the spacing between plants $(10$ and $20 \mathrm{~cm})$. The variables analyzed were the number and mass of commercial and bad grains. The results evidenced that there was no significant interaction between the factors system of cultivation and spacing between the plants for all analyzed variables. It was concluded that there was no significant effect of the spacing between the plants on the production of commercial and bad grains, and the drip system was superior for the production of commercial and bad grains, with a lower percentage of bad grains than the dry system .

KEYWORDS: Drip; dry; plant density

\section{INTRODUÇÃO}

$\mathrm{O}$ amendoim (Arachis hypogaea $\mathrm{H}$.) é uma leguminosa originada do sul da América, pertencente à família Fabaceae. É muito valorizado por ser rico em óleo, proteínas e vitaminas e por ser fonte de energia e aminoácidos. Devido a isso, essa cultura agrega bom valor no mercado interno e externo, e sua produção vem crescendo em todo território nacional (HEID et al., 2015; MENEGHETTE et al., 2017).

Na região Nordeste, o amendoim é cultivado, na maioria, por agricultores que possuem baixo nível tecnológico, dessa forma, obtendo baixas produtividades (ALMEIDA et al., 2014). Todavia, com a adoção de cultivares precoces e tolerantes ao déficit hídrico, a cultura torna-se um grande potencial produtivo para os agricultores da região (VASCONCELOS et al., 2015).

A deficiência hídrica é um fator prejudicial ao desenvolvimento da cultura, juntamente com a temperatura e a radiação. Necessita de uma faixa de precipitação de 500 a $700 \mathrm{~mm}$ durante o ciclo para a máxima produção. A cultura do amendoim pode ser explorada tanto no sistema irrigado quanto no sequeiro. Em relação ao cultivo em sequeiro, o sistema irrigado proporciona o controle da precipitação, característica indispensável para a cultura, pois, durante o ciclo, requer períodos com maior e menor oferta de água, sendo o florescimento o período de maior sensibilidade a falta de água e a colheita a época em que se apresenta a menor necessidade de água (SILVEIRA et al., 2013; CARVALHO, et al., 2014; GOULART et al., 2017).

A produção em sistema de sequeiro proporciona menores custos, pois utiliza de recursos naturais, como a água da chuva e radiação. Além disso, o amendoim tem como característica a alta profundidade de raízes, o que possibilita o melhor aproveitamento na absorção de água do solo. Porém, tanto para o sequeiro como para o irrigado, deve-se realizar o manejo adequado de espaçamento e semeadura para maximizar a produção (SILVEIRA et al., 2015; BARBIERI, et al., 2016).

O espaçamento é fundamental para o máximo aproveitamento dos fatores ambientais como a radiação e a água, além de outros benefícios como o controle da maturação, além de auxiliar no controle das plantas invasoras, com aumento no aproveitamento de nutrientes e luz. Esse espaçamento pode ser testado e adaptado às diferentes cultivares, já que o crescimento das plantas varia com as condições climáticas de cada região (SILVEIRA et al., 2013; HEID et al., 2015).

Para o correto estabelecimento de uma população de plantas no cultivo do amendoim é preciso considerar a cultivar adotada, o tipo de solo, a adubação, os 
fatores climáticos, a época de semeadura e o sistema de colheita utilizado (SILVEIRA et al., 2015).

Com base nisso, o presente trabalho teve como objetivo avaliar a produção de grãos comerciais, de grãos inadequados, e a porcentagem de grãos inadequados para os sistemas de sequeiro e irrigado, em função do espaçamento entre as plantas.

\section{MATERIAL E MÉTODOS}

O experimento foi realizado no período de março a junho de 2017, no Centro de Ciências Agrárias e da Biodiversidade (CCAB), na Universidade Federal do Cariri (UFCA), com altitude de 442 m, e coordenadas geográficas de latitude sul $7^{\circ} 14^{\prime}$ 3,4" e longitude oeste $39^{\circ} 22^{\prime}$ 7,6”. Apresenta classificação climática Aw', de acordo com KÖEPPEN (1948), sendo considerado clima tropical com inverno seco. As precipitações são, geralmente, superiores a $750 \mathrm{~mm}$ por ano nestas regiões de clima Aw', sendo encontrado nas serras do Ceará (EMBRAPA 2016).

O solo da área experimental foi classificado como Argissolo Vermelho Amarelo, de textura arenosa, conforme classificação de média intensidade do mapa de solos da FUNCEME (2012). A constituição química na camada de $0-20 \mathrm{~cm}$ foi: $\mathrm{pH}$ (1:2,5 H2O): 5,9; P (melich $\left.{ }^{-1}\right): 5,72 \mathrm{mg} \mathrm{dm}^{-3}$; K: 1,90 mmolc dm ${ }^{-3}$; Ca: 15,3 mmolc $\mathrm{dm}^{-3}$; Mg: 5,0 mmolc dm${ }^{-3}$; CTC: $33,0 \mathrm{mmolc} \mathrm{dm}^{-3}$ e V (\%): 68,5.

O delineamento utilizado foi em blocos casualizados, em esquema de parcela subdividida, com quatro repetições. A parcela foi o sistema de cultivo do amendoim (Gotejo suplementar e sequeiro), e a subparcela foi o espaçamento entre plantas (10 e $20 \mathrm{~cm}$ ).

As unidades experimentais consistiram de três fileiras duplas, com espaçamento de 0,3 m entre as fileiras na dupla e de 0,6 m entre as duplas, com três metros de comprimento, totalizando uma área por parcela de $8,1 \mathrm{~m}^{2}(2,7 \times 3 \mathrm{~m})$. Foi considerada como área útil, apenas a fileira dupla central, com um metro de comprimento $\left(0,9 \mathrm{~m}^{2}\right)$, excluindo-se as duas fileiras duplas das laterais e um metro de cada extremo da parcela, considerado como bordadura para reduzir o efeito dos demais tratamentos.

$\mathrm{Na}$ área com irrigação por gotejo complementar, as mangueiras de gotejo foram instaladas com espaçamento de $0,9 \mathrm{~m}$, com as fileiras de amendoim sendo semeadas a 0,15 $\mathrm{m}$ de cada lado, o que garante o espaçamento desejado entre as fileiras nas duplas e entre as fileiras duplas, mantendo o mesmo arranjo utilizado no sistema de sequeiro.

$\mathrm{Na}$ área experimental o preparo do solo foi feito com grade leve. Em seguida foram abertos sulcos com $10 \mathrm{~cm}$ de profundidade para todos os tratamentos. Foi realizada a adubação de semeadura com $300 \mathrm{~kg} \mathrm{ha}^{-1}$ da formulação 4-30-20 e colocado solo sobre o adubo, evitando o contato da semente com o adubo.

A semeadura foi realizada no dia 10 de março de 2017, depositando-se uma semente de amendoim a cada 10 ou $20 \mathrm{~cm}$, conforme cada tratamento, por este ser um fator de estudo, totalizando o uso total de 222.222 e 111.111 sem ha-1, respectivamente. Em seguida cobriram-se as sementes com solo.

A cultivar de amendoim utilizada foi a BRS151L7, desenvolvida pela Embrapa para a região nordeste, de porte ereto e com ciclo reduzido de apenas 90 dias. Os tratos culturais consistiram de duas capinas manuais para controle de plantas daninhas, e a amontoa que foi realizada na época do florescimento, prática esta indispensável para o amendoim de porte ereto, promovendo o desenvolvimento de mais vagens por planta. 
A colheita foi realizada no dia 10 de junho de 2017, retirando-se as vagens do solo e mantendo-se as plantas com as vagens reviradas para cima no campo, para secagem natural pelo sol, com duração de cinco dias. Após a colheita, a irrigação foi suspensa.

As variáveis analisadas foram: o número e a massa de grãos comerciais e inadequados. A separação dos grãos quanto à qualidade foi realizada pela aparência dos grãos, os que apresentavam deficiência no crescimento (chochos) ou ataque de pragas e doenças foram considerados inadequados. Estas variáveis foram obtidas pela contagem e pesagem de todos os grãos comerciais e não comerciais contidos nas vagens da área útil da unidade experimental, sendo expressos em unidade $\mathrm{m}^{-1} \mathrm{e} \mathrm{g} \mathrm{m}^{-1}$, respectivamente.

Foram determinadas também as porcentagens de grãos inadequados, pela relação entre a quantidade e a massa de grãos inadequados pela quantidade e a massa de grãos total, considerando-se a relação com base em unidade e massa, respectivamente. Os dados foram submetidos à análise de variância e os resultados significativos foram comparados pelo teste de tukey a $5 \%$ de probabilidade.

\section{RESULTADOS E DISCUSSÃO}

De acordo com os resultados é possível observar na tabela 1 que não ocorreu interação significativa entre os fatores sistema de cultivo e espaçamento entre as plantas para o número de grãos comerciais, grãos inadequados por metro e para porcentagem de grãos inadequados com base em unidades de grãos de amendoim.

TABELA 1. Síntese da análise de variância e do teste de médias para o número de grãos comerciais, o número de grãos inadequados, e a porcentagem de grãos inadequados (unid/unid).

Grãos Comerciais

Fontes de Variação
Grãos Inadequados
\% Grãos Inadequados

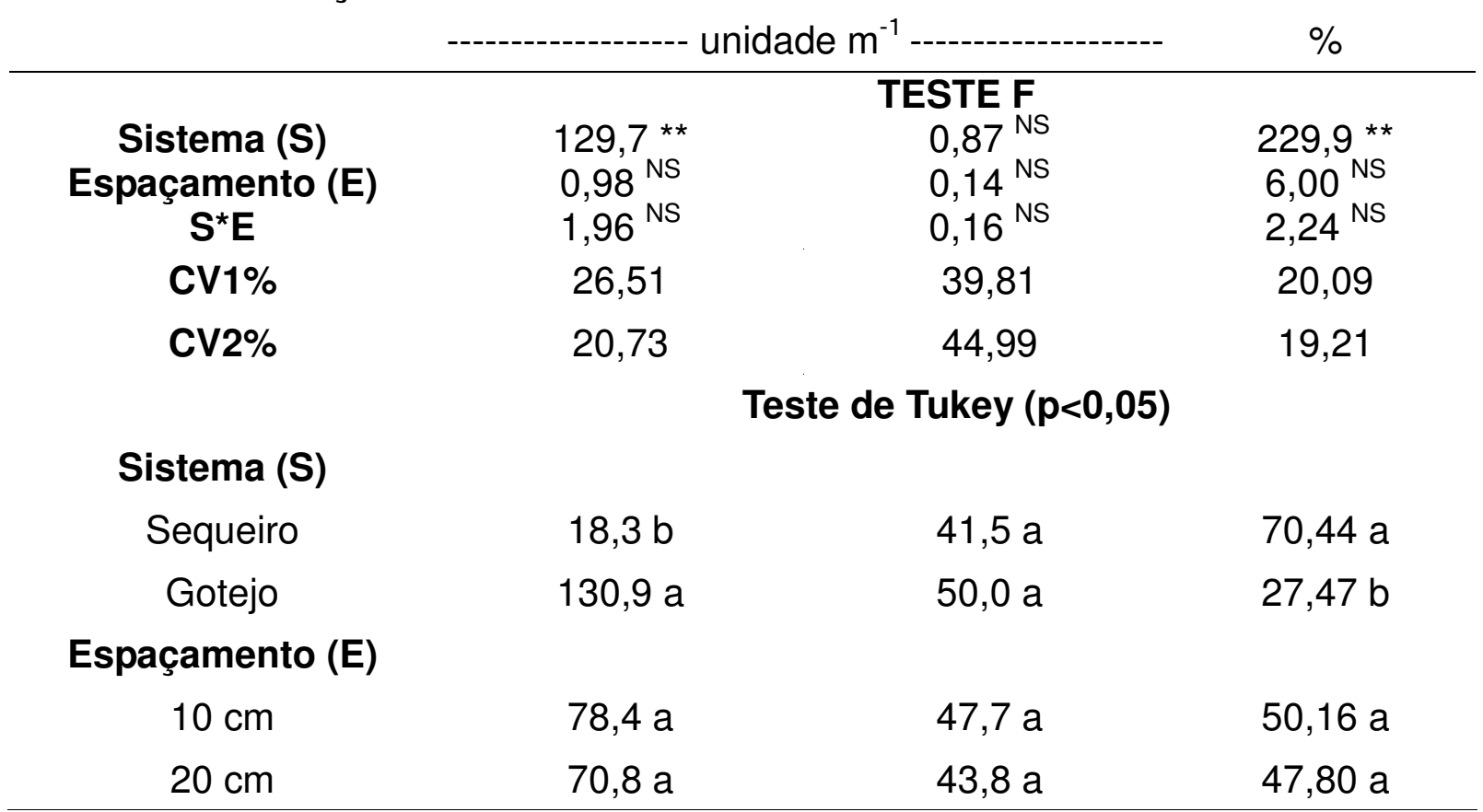

Médias seguidas pela mesma letra minúscula na coluna, não diferem entre si pelo teste de Tukey a 5\% de probabilidade. ${ }^{\star *}$ : significativo $(P<0,01)$; *: significativo $(P<0,05)$; NS: não significativo; CV\%: coeficiente de variação. 
Observou-se, ainda, nos resultados da Tabela 1, que para os diferentes sistemas, as médias para o número de grãos inadequados por metro não resultaram em diferença significativa, apresentando números semelhantes de grãos inadequados entre os sistemas de sequeiro e irrigado. Porém, houve diferença estatística significativa entre as médias para o número de grãos comerciais por metro e porcentagem de grãos inadequados (unid/unid), sendo a média de grãos comerciais superior no sistema com gotejo complementar e a média da porcentagem de grãos inadequados maior no sistema de sequeiro.

Esses resultados reforçam a afirmação de RAO et al. (1988), de que a deficiência hídrica reduz a produção de flores, e o efeito é proporcional, diminuindo sensivelmente o número de vagens por planta, uma vez que há redução na produção de fotoassimilados. Fato este que eleva a porcentagem de vagens e grãos chochos, influenciados pela disponibilidade de água (SILVA et al., 1998).

Em relação ao espaçamento entre as plantas, não houveram diferenças estatísticas significativas entre as médias para as variáveis estudadas. Resultado semelhante ao de SILVEIRA et al. (2015), que também não encontraram diferenças significativas em diferentes espaçamentos para a produção de amendoim. $O$ amendoim apresentou boa compensação na produção individual das plantas, pois para o espaçamento de $20 \mathrm{~cm}$ entre as plantas foi depositada a metade da quantidade de sementes utilizadas para o espaçamento de $10 \mathrm{~cm}$, e mesmo assim apresentou produtividades de grãos comerciais e inadequados similares.

Verifica-se com os resultados da Tabela 2, que não ocorreu interação significativa entre os fatores sistema de cultivo e espaçamento entre as plantas para a massa de grãos comerciais e inadequados por metro, e para porcentagem de grãos inadequados.

TABELA 2. Síntese da análise de variância e do teste de médias para a massa de grãos comerciais, a massa de grãos inadequados, e a porcentagem de grãos inadequados $(\mathrm{g} / \mathrm{g})$.

$\begin{array}{lccc}\text { Fontes de Variação } & \text { Grãos Comerciais } & \begin{array}{c}\text { Grãos } \\ \text { Inadequados }\end{array} & \begin{array}{c}\% \text { Grãos } \\ \text { Inadequados }\end{array} \\ & -\cdots-\mathrm{g} \mathrm{m}^{-1} & & \%\end{array}$

\begin{tabular}{cccc} 
& TESTE F & $\%$ \\
\hline Sistema (S) & $229,9^{* *}$ & $73,68^{* *}$ & $26,11^{*}$ \\
Espaçamento (E) & $5,00^{\mathrm{NS}}$ & $2,77^{\mathrm{NS}}$ & $0,58^{\mathrm{NS}}$ \\
SEE $_{\text {CV1\% }} \%$ & $2,24^{\mathrm{NS}}$ & $0,11^{\mathrm{NS}}$ & $0,07^{\mathrm{NS}}$ \\
CV2\% & $20,09^{*}$ & 18,52 & 38,74 \\
& 19,21 & 24,05 & 63,01
\end{tabular}

\section{Sistema (S)}

$\begin{array}{cccc}\text { Sequeiro } & 10,9 \mathrm{~b} & 4,7 \mathrm{~b} & 36,6 \mathrm{a} \\ \text { Gotejo } & 80,1 \mathrm{a} & 11,0 \mathrm{a} & 12,4 \mathrm{~b}\end{array}$

Espaçamento (E)

$\begin{array}{llll}10 \mathrm{~cm} & 50,8 \mathrm{a} & 7,1 \mathrm{a} & 21,5 \mathrm{a} \\ 20 \mathrm{~cm} & 40,1 \mathrm{a} & 8,7 \mathrm{a} & 27,5 \mathrm{a}\end{array}$


De acordo com os resultados, ainda da Tabela 2, é possível verificar que houveram diferenças estatísticas significativas entre as médias para todas as variáveis analisadas nos diferentes sistemas de cultivo, sendo a média da massa de grãos comerciais e inadequados por metro superior no sistema de gotejo em relação ao de sequeiro. A média da porcentagem de grãos inadequados no sistema de sequeiro superou o sistema de gotejamento. Resultados que são semelhantes aos de SILVA et al. (1998) que observaram que a menor disponibilidade hídrica, proporcionou o menor rendimento de amendoim em grãos, como também Barbieri et al. (2016) trabalhando com amendoim em condição de sequeiro, com quatro épocas distintas de semeadura, também verificaram redução acentuada na produtividade de grãos para as épocas mais tardias, com menor disponibilidade hídrica.

Como na Tabela 1, também não houveram diferenças estatísticas significativas entre as médias, para nenhuma das variáveis, em relação ao espaçamento entre as plantas, com a produtividade de grãos comerciais e não comerciais por metro sendo semelhantes para os espaçamentos estudados. Resultado este que difere de Barbieri et al. (2016) que com menor densidade de plantas (espaçamento $20 \mathrm{~cm}$ ) obtiveram menor produtividade do que para a maior densidade (espaçamento $10 \mathrm{~cm}$ ).

\section{CONCLUSÃO}

Os espaçamentos de 10 ou $20 \mathrm{~cm}$ entre as plantas não alteram a produção de grãos comerciais e inadequados. O sistema de gotejo apresenta maior número e massa de grãos comerciais e inadequados por metro e menor porcentagem de grãos inadequados em relação ao sistema de sequeiro.

\section{AGRADECIMENTOS}

À Universidade Federal do Cariri pelo espaço e recursos concedidos para o experimento e ao PET Agronomia pela bolsa concedida aos graduandos.

\section{REFERÊNCIAS}

ALMEIDA, A. T.; PEIXOTO, C. P.; BLOISI, L.F. M. ; OLIVEIRA, J. DA S.; POELKING, V. G. DE C. Avaliação morfológica e produtiva de amendoim produzido por pequenos agricultores do Recôncavo da Bahia. Revista da Caatinga, v. 27, n. 3, p. 150-159, 2014). Disponível em: http://www.redalyc.org/articulo.oa?id=237132104017>

BARBIERI, J. D.; DALLACORT, R. ; FARIA JUNIOR, C. A. ; DE FREITAS, P. S. L.; FENNER, W. Ensaio de épocas e densidade de plantas de duas cultivares de amendoim. Nucleus, v. 13, n. 1, 2016. Disponível em: < http://www.nucleus.feituverava.com.br/index.php/nucleus/article/view/1599 > DOI: 10.3738/1982.2278.1599

CARVALHO, T. L.; DA ROCHA, A. C.; BASTOS, F. J. DE C.; CUNHA, F. N.; DA SILVA, N. F.; SOARES, F. A. L. Genótipos de amendoim cultivados em semeadura direta e convencional sob regime hídrico do Sudoeste Goiano. Revista Brasileira de Agricultura Irrigada, v.8, $\mathrm{n}^{\circ} .6, \mathrm{p} .432$ - 443, 2014. Disponível em: < http://www.inovagri.org.br/revista/index.php/rbai/article/view/244/pdf_194> DOI: 10.7127/rbai.v8n600244 
EMBRAPA,

Clima.

Disponível

em:<

http://www.cnpf.embrapa.br/pesquisa/efb/clima.htm >. Acesso em: 23 de março de

2016.

FUNCEME - Fundação Cearense de Meteorologia e Recursos Hídricos . 2012. Levantamento de reconhecimento de média intensidade dos solos da Mesorregião do Sul Cearense / Fundação Cearense de Meteorologia e Recursos Hídricos. Fortaleza.

GOULART, D. F.; DE ALMEIDA, R. P.; RESENDE, K. C.; DA COSTA, F. A. M.; BEZERRA, J. R. C. O desafio da estruturação da cadeia produtiva do amendoim no semiárido do Nordeste. Organizações Rurais \& Agroindustriais, v. 19, n. 1, p. 4759, 2017. Disponível em: < http://200.131.250.22/revistadae/index.php/ora/article/view/1079/547 > DOI: 10.21714/2238-68902017v19n1p047

HEID, D. M.; ZÁRATE, N. A. H.; OHLAND, R. A. A.; TORALES, E. P.; MORENO, L. B.; VIEIRA, M. DO C. Produtividade agronômica de genótipos de amendoim Virginia cultivados com diferentes espaçamentos entre fileiras no canteiro. Revista de Ciências Agrárias, v. 39, n. 1, p. 105-113, 2016. Disponível em: < http://www.scielo.mec.pt/pdf/rca/v39n1/v39n1a12.pdf> DOl: http://dx.doi.org/10.19084/RCA15058

KÖPPEN, W. 1948. Climatologia: con un estudio de los climas de la tierra. Fondo de Cultura Econômica. México. 479p.

MENEGHETTE, H. H. A.; LARAZARINI, E. ; BOSSOLANI, J. W. ; PARRA, L. F. ; HAYASHI, F. K. 2017; Doses de fósforo e potássio em plantas de amendoim na presença e ausência de adubação foliar. Brazilian Journal of Biosystems Engineering, v. 11, n. 2, p. 125-134, 2017. Disponível em: <http://seer.tupa.unesp.br/index.php/BIOENG/article/view/513/325>

DOI: http://dx.doi.org/10.18011/bioeng2017v11n2p125-134

RAO, R.C.N.; WILLIAMS, J.H.; SIVAKUMAR, M.V.K.; WADIA, K.D.R. Effect of water deficit at different growth phases of peanut. II. Response to drought during preflowering phase. Agronomy Journal, Madison, v.80, p.431-438, 1988

SILVA, L. C.; BELTRAO, N. E. de M.; RAO, T. V. R; FIDELES FILHO, J. Efeito do manejo da Irrigação na qualidade da produção e na produtividade do amendoim CV. BR1. Revista Brasileira de Engenharia Agrícola e Ambiental. 1998, v.2, n.2, pp.175-178. ISSN 1415-4366. Disponível em: <http://www.scielo.br/scielo.php?script=sci_arttext\&pid=S1415-

43661998000200175\&lng=en\&nrm=iso> DOI: http://dx.doi.org/10.1590/18071929/agriambi.v02n02p175-178.

SILVEIRA, P. S. DA; PEIXOTO, C. P.; LEDO, C. A. DA S.; PASSOS, A. R.; BORGES, V. P.; BLOISI, L. F. M. Fenologia e produtividade do amendoim em diferentes épocas de semeadura no Recôncavo Sul Baiano. Bioscience Journal, v. 29, n. 3, p. 553-561, 2013. Disponível em: < http://www.seer.ufu.br/index.php/biosciencejournal/article/view/13437/12496> 
SILVEIRA, P. S. DA; PEIXOTO, C. P.; LEDO, C. A. DA S.; LIMA, V. P. DE; SANTOS, A. P. S.; NAKAGAWA, J. Alocação de fitomassa e índice de colheita de amendoim em diferentes épocas e densidades de semeadura. Magistra, v. 27, n. 3/4, p.367-375, $2015 . \quad$ Disponível em: https://magistraonline.ufrb.edu.br/index.php/magistra/article/view/404/213>

VASCONCELOS, F. M. T. DE; VASCONCELOS, R. A. DE; LUZ, L. N. DA; CABRAL, N. T.; DE OLIVEIRA JUNIOR, J. O. L.; SANTIAGO, A. D.; SGRILLO, E.; FARIAS, F. J. C.; MELO FILHO, P. DE A.; SANTOS, R. C. DOS. Adaptabilidade e estabilidade de genótipos eretos de amendoim cultivados nas regiões Nordeste e Centro-Oeste. Ciência Rural, v. 45, n. 8, p. 1375-1380, 2015. Disponível em: < http://www.scielo.br/pdf/cr/v45n8/0103-8478-cr-45-08-01375.pdf> 